Biochimica et Biophysica Acta, 628 (1980) 451-467

(C) Elsevier/North-Holland Biomedical Press

BBA 29206

\title{
BINDING OF ADENOSINE DIPHOSPHATE TO HUMAN BLOOD PLATELETS AND TO ISOLATED BLOOD PLATELET MEMBRANES
}

\author{
JOOST P.M. LIPS, JAN J. SIXMA and MARION E. SCHIPHORST \\ Department of Haematology, University Hospital, Catharijnesingel 101, 3500 CG Utrecht \\ (The Netherlands)
}

(Received August 1st, 1979)

Key words: ADP binding; Platelet membrane

\section{Summary}

The equilibrium binding of ${ }^{14} \mathrm{C}$-labeled ADP to intact washed human blood platelets and to platelet membranes was investigated. With both intact platelets and platelet membranes a similar concentration dependence curve was found. It consisted of a curvilinear part below $20 \mu \mathrm{M}$ and a rectilinear part above this concentration. At high ADP concentrations, the rectilinear part appeared to be saturable. Because of this, two classes of saturable ADP binding sites were proposed. ADP was partly converted to ATP and AMP with intact platelets while this conversion was virtually absent in isolated platelet membranes. ADP was bound to platelet membranes with the same type of curves found for intact platelets.

The ADP binding to the high affinity system, which was stimulated by calcium ions, was nearly independent of temperature and had a $\mathrm{pH}$ optimum at 7.8 .

A number of agents were investigated for inhibiting properties. Of the sulfhydryl reagents only $p$-chloromercuribenzene sulfonate inhibited both high and low affinity binding systems while iodoacetamide and $N$-ethylmaleimide were without effect. Compounds acting via cyclic AMP on platelet aggregation, such as adenosine and cyclic AMP itself, had no influence on binding. Some nucleosidediphosphates and nucleotide analogs at a concentration of $100 \mu \mathrm{M}$ had no, or only a slight, effect on high affinity ADP binding. For some other nucleotides inhibitor constants were determined for both platelet ADP aggregation

\footnotetext{
Abbreviations: NDP kinase, ATP : nucleosidediphosphate phosphotransferase (EC 2.7.4.6); $\mathrm{AMPP}\left(\mathrm{CH}_{2}\right) \mathrm{P}$, adenyl-5'-yl-( $\beta, \gamma$-methylene)diphosphonate; $A M P\left(C_{2}\right) P$, adenyl-5'-yl-( $\alpha, \beta$-methylene)phosphonate; (2- $O$ thio)ADP, adenosine $5^{\prime}$-(2-O-thio)diphosphate: $\mathrm{FSO}_{2}-\mathrm{Bz}$-Ado, $5^{\prime}$-fluorosulfonylbenzoyl adenosine; $\operatorname{AMP}\left(\mathrm{CH}_{2}\right) \mathrm{PP}$, adenyl-5'-yl-( $\alpha, \beta-$ methylene $)$ diphosphate.
} 
and ADP binding. The inhibitor constants of ATP, adenyl-5'-yl-( $\beta, \gamma$-methylene)diphosphate, IDP, adenosine-5'-(2-O-thio)diphosphate, for aggregation and high affinity binding were in good correlation with each other. Exceptions formed fluorosulfonylbenzoyl adenosine and AMP.

The ATP formation found with intact platelets could be attributed to a nucleosidediphosphate kinase. It was investigated in some detail. The enzyme was magnesium dependent, had a $Q_{10}$ value of 1.41 , a pH optimum at 8.0, was competitively inhibited by AMP and reacted via a ping pong mechanism.

All findings described in this paper indicate that platelets as well as platelet membranes bind ADP with the same characteristics and they suggest that the high affinity binding of ADP is involved in platelet aggregation induced by ADP. The results on nucleosidediphosphate kinase did not permit a firm conclusion about the role of the enzyme in induction of platelet aggregation by ADP.

\section{Introduction}

The detection of the ADP induced aggregation of platelets by Gaarder [1] was followed by many investigations into the nature of the interaction between ADP and platelets. It was demonstrated that ADP is not taken up into the platelets $[2,3]$. In platelet rich plasma ADP is degraded to adenosine and this is transported and converted intracellularly into adenine nucleotides [4,5]. The uptake of adenosine did not correlate with aggregation [6], and adenosine appeared to be an inhibitor of ADP induced aggregation [7]. On the basis of these data it was assumed that ADP exerts its effect on the outside of the platelet. Boullin et al. [8] indicated that platelets may bind $\left[{ }^{14} \mathrm{C}\right] \mathrm{ADP}$. This was investigated in more detail by Born and Feinberg [9] who demonstrated that the rapid initial association of ADP with the platelets represented binding whereas the later increase in radioactivity was caused by intracellular accumulation of adenosine which was formed due to ADP degradation in platelet rich plasma.

Binding to isolated platelet membranes was studied extensively by Nachman and Ferris [10]. The binding of ADP to membranes, prepared by pestle homogenization in an EDTA containing medium, was a slow process which was not yet maximal after $60 \mathrm{~min}$. This suggests that these investigators studied exchange of $\left[{ }^{14} \mathrm{C}\right]$ ADP with non-labeled ADP that had become bound to the membranes during the homogenization. Binding of $\left[{ }^{14} \mathrm{C}\right] \mathrm{ADP}$ to membranes prepared with the glycerol lysis technique [11] differed [12,13] from binding to those of Nachman and Ferris [10] but also from binding obtained with intact platelets [9]. This was reason for us to reinvestigate the issue. We present here the results of a detailed study of the binding of $\left[{ }^{14} \mathrm{C}\right] \mathrm{ADP}$ to washed platelets and to isolated platelet membranes. ADP appeared to bind with the same characteristics in both cases. One of the potential ADP receptor molecules [14-16], nucleosidediphosphate kinase (EC 2.7.4.6; ATP : nucleosidediphosphate phosphotransferase, (NDP kinase)) was shown to be present on both platelets and membranes. Differences in optimal conditions for binding and NDP kinase activity were demonstrated, but these do not necessarily indicate 
that NDP kinase should not be considered as the potential functional ADP receptor.

\section{Experimental procedures}

\section{Materials}

[8. $\left.{ }^{14} \mathrm{C}\right] \mathrm{ADP}$ (spec. act. 55-60 Ci/mol), [U. $\left.{ }^{14} \mathrm{C}\right] \mathrm{ADP}$ (spec. act. $560-600 \mathrm{Ci}$ / $\mathrm{mol}$ ), $\left[\mathrm{U} \cdot{ }^{14} \mathrm{C}\right]$ sucrose (spec. act. $381 \mathrm{Ci} / \mathrm{mol}$ ) and $\left[8-{ }^{14} \mathrm{C}\right] \mathrm{ATP}$ (spec. act. $55-60$ $\mathrm{Ci} / \mathrm{mol}$ ) were obtained from Radiochemical Centre, Amersham, U.K., as ammonium salts. At least $97 \%$ of the label was ADP, as analyzed by high voltage electrophoresis. A slow degradation to AMP, even when stored at $-20^{\circ} \mathrm{C}$, was observed. The solution was discarded when less than $90 \%$ of the label was found as ADP. Stock solutions were diluted with saline to appropriate concentrations, which were stored at $-20^{\circ} \mathrm{C}$.

ADP; ATP; AMP; UDP; CDP; IDP; adenyl-5'-yl-( $\beta, \gamma$-methylene)diphosphonate (AMPP $\left.\left(\mathrm{CH}_{2}\right) \mathrm{P}\right)$; ITP; GTP; adenosine $5^{\prime}$-(2-O-thio)diphosphate, ((2-Othio)ADP) as respective sodium salts; and adenosine deaminase (adenosine aminohydrolase, EC 3.5.4.4) were purchased from Boehringer Mannheim, F.R.G. Apyrase (ATP diphosphohydrolase, EC 3.6.1.5); phenylmethylsulfonylfluoride; adenosine; $N$-benzoylcarbonyl-L- $\alpha$-glutamyl-L-tyrosine; adenyl-5'-yl$\left(\alpha, \beta\right.$-methylene)phosphonate, $\left(\mathrm{AMP}\left(\mathrm{CH}_{2}\right) \mathrm{P}\right) ; \quad$ adenyl-5' -yl- $(\alpha, \beta$-methylene $)$ diphosphate $\left(\mathrm{AMP}\left(\mathrm{CH}_{2}\right) \mathrm{PP}\right)$ and $5^{\prime}$-fluorosulfonylbenzoyl adenosine, $\left(\mathrm{FSO}_{2}\right.$ Bz-Ado) were obtained from Sigma Chemicals, St. Louis, MO, U.S.A. All other chemicals used were analytical grade.

\section{Methods}

Isolation of platelets: Blood was obtained from volunteers, 9 vols. into 1 vol. of $0.113 \mathrm{M}$ disodium citrate and platelet-rich plasma was made by centrifugation for $10 \mathrm{~min}$ and $275 \times g_{\max }$ at room temperature. The platelets in the resulting platelet-rich plasma were washed free from plasma by means of gel filtration into a calcium- and magnesium-free Tyrode solution according to Walsh [17]. These platelets were recalcified directly after gel filtration by adding a calcium chloride solution to a concentration of $2 \mathrm{mM}$.

For isolation of platelet membranes, use was made of platelet concentrates obtained from the hospital blood bank. They were made by differential centrifugation of $450 \mathrm{ml}$ whole blood obtained from healthy donors. As anticoagulant $50 \mathrm{ml}$ of $0.14 \mathrm{M}$ citrate and $0.128 \mathrm{M}$ glucose was used. Contaminating red blood cells and plasma were removed by centrifugation for $10 \mathrm{~min}$ at $275 \times$ $g_{\max }$ and room temperature. The platelet rich plasma was gel filtered over a Sepharose 2B column in a buffer, $\mathrm{pH} 7.4$, which consisted of $0.15 \mathrm{M} \mathrm{NaCl}$, $0.01 \mathrm{M}$ Tris-HCl and $1 \mathrm{mM}$ EDTA (Tris-saline-EDTA buffer). The effluent platelets were directly collected on an isotonic linear $0-40 \%(w / v)$ glycerol gradient. Platelet numbers were determined with a Thrombocounter (Coulter Electronics, Harpenden, U.K.).

Isolation of platelet membranes. The washed platelets on the glycerol gradient were lysed using the glycerol lysis technique of Barber and Jamieson [11], with minor modifications: the lysis buffer, $\mathrm{pH} 7.4$, consisted of $0.15 \mathrm{M}$ $\mathrm{NaCl}$ with $0.01 \mathrm{M}$ Tris- $\mathrm{HCl}$, apyrase $(0.1 \mathrm{mg} / \mathrm{ml})$, adenosine deaminase $(0.1$ 
$\mathrm{U} / \mathrm{ml})$ phenylmethylsulfonylfluoride $(0.4 \mathrm{mM})$ and $N$-benzoylcarbonyl-L- $\alpha$ glutamyl-L-tyrosine $(0.5 \mathrm{mM})$ according to Nachman [18]. Membranes were separated from the lysate by centrifugation over a discontinuous $20 \%(\mathrm{w} / \mathrm{v})$ sodium metrizoate $(d: 1.120)$ gradient [11]. The membranes were carefully isolated from the interface by aspiration with a pipet. The isolated membrane fraction was washed once by centrifugation in a Beckman L3-50 ultracentrifuge $\left(60 \mathrm{~min}, 105000 \times g_{\max }, 1^{\circ} \mathrm{C}\right)$. The pellet was resuspended in Tris-saline buffer and stored at $-20^{\circ} \mathrm{C}$. The amount of membranes harvested was estimated by protein determination according to Lowry et al. [19] with cristalline bovine serum albumin as standard. Normally $2.5-3.5 \mathrm{mg}$ membrane protein was obtained from $10^{10}$ platelets. The membranes were characterized by absence of lactate dehydrogenase (L-Lactate $: \mathrm{NAD}^{+}$oxidoreductase, $\mathrm{EC}$ 1.1.1.27) activity, a molar cholesterol/phospholipid ratio of 0.62 and contained about $50 \%$ of the platelet sialic acid. The recovery of membranes was assayed with ${ }^{125} \mathrm{I}$ labeled $\mathrm{Fab}$ fragments (from a rabbit antiserum against human platelet membranes) bound to platelets. $15 \%$ of total platelet protein and $40 \%$ of the platelet-associated radioactivity was localized in the membrane fraction, indicating an enrichment of about three.

ADP binding studies. The binding of ADP to washed platelets was measured by an ultrafiltration technique. To $725 \mu \mathrm{l}$ of a washed platelet suspension in a polyethylene tube, $40 \mu \mathrm{l}$ of $40 \mathrm{mM} \mathrm{CaCl}_{2}$ in Tris-saline buffer ( $\mathrm{pH} \mathrm{7.4)} \mathrm{was}$ added, and the tube was incubated at $37^{\circ} \mathrm{C}$. After $30 \mathrm{~min} 85 \mu \mathrm{l}$ of a $\left[{ }^{14} \mathrm{C}\right]$ ADP solution was added, and the incubation was continued, after mixing, for 10 min. Then samples of $250 \mu \mathrm{l}$ were taken in triplicate. In studies with isolated membranes, $100 \mu \mathrm{l}$ of a membrane suspension, protein concentration varying from $0.2-0.6 \mathrm{mg} / \mathrm{ml}$, was incubated for $4 \mathrm{~min}$ at $37^{\circ} \mathrm{C}$ in a polyethylene tube together with $50 \mu \mathrm{l}$ of $8 \mathrm{mM} \mathrm{CaCl}{ }_{2}$ in Tris-saline buffer. Then $50 \mu \mathrm{l}$ of a $\left[{ }^{14} \mathrm{C}\right]$ ADP solution was added and samples of $50 \mu \mathrm{l}$ were taken in triplicate after another $10 \mathrm{~min}$ incubation.

The samples were filtered over $0.80 \mu \mathrm{m}$ or $0.45 \mu \mathrm{m}$ Millipore filters (platelets and membranes, respectively), (Millipore Corp., Bedford, MA, U.S.A.) by vacuum aspiration. The filters were washed twice with $6 \mathrm{ml}$ of saline (preliminary experiments had shown that more than two washings did not reduce further the radioactivity adhering to the filters). The washing procedure took about $10 \mathrm{~s}$ and the filters were transferred to scintillation vials. $1 \mathrm{ml}$ of ethylene glycol monomethyl ether (Merck, Darmstadt, F.R.G.) was used to dissolve the filters, $5 \mathrm{ml}$ Emulsifier Scintillator (Packard, Downers Grove, IL, U.S.A.), was added, for measuring the radioactivity in either an Isocap 300 (Nuclear Chicago) or a Packard 3380 Tricarb Liquid scintillation spectrometer. No correction for non-specific binding was applied because the low affinity binding of ADP would have been missed. The amount of binding was calculated from the specific radioactivity of the used solution and the radioactivity adhered to the filters after correction for adsorption of $\left[{ }^{14} \mathrm{C}\right] \mathrm{ADP}$ to the filters.

The nature of the radioactivity bound to the platelets was determined by extraction of the filter, after sample filtration, with $200 \mu \mathrm{l}$ ice cold $0.1 \mathrm{M}$ EDTA/ethanol/saline $(1: 9: 10, \mathrm{v} / \mathrm{v} / \mathrm{v})$ mixture, $\mathrm{pH} 7.6$ [20]. A sample of the extract was subjected to high voltage electrophoresis and radioactivity of metabolites was determined as described previously $[5,21]$. In a few experi- 
ments $\mathrm{ADP}$ binding to intact platelets was determined with the centrifugation technique used by Born and Feinberg [9] with minor modifications. Instead of a silicon based oil layer a mixture of $0.5 \mathrm{ml}$ dibutylphthalate and dinonylphthalate $(60: 40, \mathrm{v} / \mathrm{v})$ was used. After centrifugation of the incubation mixture, the supernatant was discarded, and the pellet was washed twice with saline. After the tube walls had been wiped dry with a cotton wool tipped stick, the pellet was solubilized with Soluene (Packard) and, after addition of a scintillation cocktail, counted as described above. The platelet associated radioactivity was corrected for trapped solution by centrifuging separate platelet samples that had been incubated with $\left[{ }^{14} \mathrm{C}\right]$ sucrose instead of labeled ADP.

Nucleoside diphosphokinase activity. $150 \mu \mathrm{l}$ of a suspension of membranes in Tris-saline containing $1 \mathrm{mM} \mathrm{MgCl} 2$ was incubated at $37^{\circ} \mathrm{C}$ with $\left[{ }^{14} \mathrm{C}\right] \mathrm{ADP}$ together with non-radioactive ATP. After $0.5,2,4$ and 10 min incubation, samples of $50 \mu \mathrm{l}$ were taken and added to an equal volume of a mixture of one part $0.1 \mathrm{M}$ EDTA, $\mathrm{pH}$ 7.6, and nine parts ethanol (freshly prepared and kept on ice).

The extracts were electrophoresed and the nucleotides counted for radioactivity as described above. The initial velocity of ATP formation was computed from the increase of radioactivity in $\left[{ }^{14} \mathrm{C}\right] \mathrm{ATP}$ with time.

Aggregation studies. To $375 \mu \mathrm{l}$ of a recalcified platelet suspension, $25 \mu \mathrm{l}$ of human fibrinogen $(10 \mathrm{mg} / \mathrm{ml})$ (Kabi, Stockholm, Sweden) solution (in Trissaline buffer, $\mathrm{pH}$ 7.4) was added. The suspension was incubated for $20 \mathrm{~min}$ at $37^{\circ} \mathrm{C}$. The tube was then transferred to a Payton Dual Channel aggregometer (Payton Associates Inc., Scarborough, Canada) connected with an Omniscribe recorder (Houston Instr., Bel Air, CA, U.S.A.) and stirring was started. $50 \mu \mathrm{l}$ of inhibitor solution in Tris-saline buffer was added to a final concentration of 50 , 100 or $200 \mu \mathrm{M}$ and after $1 \min 50 \mu \mathrm{ADP}(5,10,100,500$ or $1000 \mu \mathrm{M})$ was added. The tangent of the line drawn through the steepest part of the aggregation curve was used to calculate the rate of aggregation. For computation of the inhibitor constants and determination of type of inhibition Dixon plots [22] were used.

Temperature and $p H$ dependence studies. $\left[{ }^{14} \mathrm{C}\right] \mathrm{ADP}$ binding was studied at seven different temperatures between 0 and $37^{\circ} \mathrm{C}$ for platelet membranes. An Arrhenius plot was constructed from the logarithms of the amount of binding and the reciprocal temperature values, and the $Q_{10}$ values were derived from this plot. The $\mathrm{pH}$ dependence study for both binding and NDP kinase activity was performed with platelet membranes suspended in Tris-saline buffer. $50 \mu \mathrm{l}$ membrane suspension was incubated for $5 \mathrm{~min}$ at $37^{\circ} \mathrm{C}$ with $100 \mu \mathrm{l}$ of a $0.2 \mathrm{M}$ Tris maleate buffer with $\mathrm{pH}$ values between 4.5 and 9.5.50 $\mu \mathrm{l}\left[{ }^{14} \mathrm{C}\right] \mathrm{ADP}$ solution was then added and binding and NDP kinase activity were determined as described above. For both temperature and $\mathrm{pH}$ dependence studies a low $(0.625 \mu \mathrm{M})$ and a high $(50 \mu \mathrm{M}) \mathrm{ADP}$ concentration were used.

\section{Results}

\section{$A D P$ binding to intact platelets}

The binding of ADP to gel filtered human blood platelets was studied in most instances with a rapid filtration technique. A rapid increase of radioactiv- 


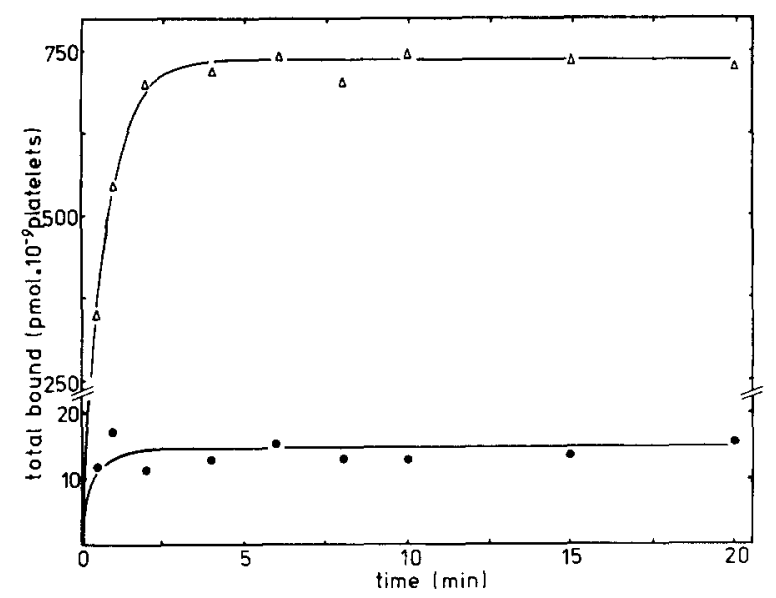

Fig. 1. Time course of total radioactivity bound to intact platelets. Binding to intact platelets was determined as described under Methods. Samples were taken at the indicated times and filtered. A representive experiment is shown. The same type of curves were found for ADP concentrations varying from $0.3 \mu \mathrm{M}-$ $20 \mathrm{mM} . \triangle \longrightarrow, 200 \mu \mathrm{M} \mathrm{ADP} ; \bullet \longrightarrow, 0.625 \mu \mathrm{M} \mathrm{ADP}$.

ity associated with platelets was found in the first 5 min and a plateau level was found after 5-10 min. This level was constant for at least the 10 subsequent min at all concentrations used (Fig. 1). Analysis of the platelet associated radioactivity revealed that about $45-55 \%$ was labeled ADP after 10 min incubation, the remaining radioactivity being for $80 \%\left[{ }^{14} \mathrm{C}\right] \mathrm{ATP}$. This was found for low and high concentrations of ADP.

The dependency of ADP binding on the $\left[{ }^{14} \mathrm{C}\right] \mathrm{ADP}$ concentration was studied at the plateau level, with gel filtered platelets, and with concentrations up to $200 \mu \mathrm{M}$. A curvilinear relationship was found below $20 \mu \mathrm{M}$, while a linear relation was found above this concentration (Fig. 2A). These kinetics can be described by assuming two binding systems: a saturable system mainly operative at low ADP concentrations and a second system which was not saturated at $200 \mu \mathrm{M}$. The system saturated at low ADP concentrations, further referred to as the high affinity system, was obtained by subtraction of the linear part by drawing a line parallel with the rectilinear part through the origin (Fig. 2A). This high affinity system was plotted according to Scatchard [23] (Fig. 2B), and an apparent association constant $\left(K_{\mathrm{a}}\right)$ and number of binding sites were derived from this plot (Table I). When all platelet associated radioactivity (ATP + ADP) was taken into account the same type of biphasic concentration dependence curve was found, with a similar association constant and number of binding sites (Table I). In a few experiments ADP binding was studied at higher ( $\mathrm{mM}$ ) concentrations. Saturation of the low affinity system was observed and a $K_{\mathrm{a}}$ of $0.49 \cdot 10^{3} \mathrm{M}^{-1}$ and a maximum binding of $32.8 \cdot 10^{6}$ binding sites/platelet was calculated (Fig. 3; mean of two experiments). This finding justified the subtraction procedure for the computation of the high affinity binding system [24]. The appearance of $\left[{ }^{14} \mathrm{C}\right] \mathrm{ATP}$ (and $\left[{ }^{14} \mathrm{C}\right] \mathrm{AMP}$ ) may indicate that part of the accumulated radioactivity is taken up after extracellular degradation of ADP to adenosine. Adenosine is transported into the platelet and metabolized 


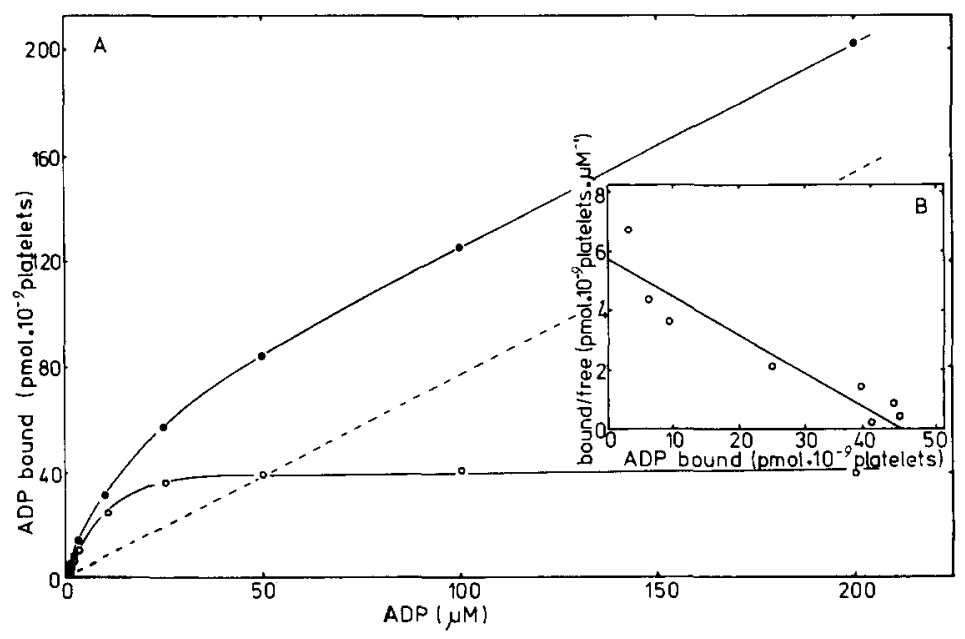

Fig. 2. (A) Concentration dependence of ADP binding to intact platelets at $\mu \mathrm{M}$ concentrations. Washed gel filtered human blood platelets were incubated at $37^{\circ} \mathrm{C}$ with different $\left[{ }^{14} \mathrm{C}\right] \mathrm{ADP}$ concentrations. Samples were taken after $10 \mathrm{~min}$ incubation in triplicate and filtered over Millipore filters $(0.8 \mu \mathrm{M})$ and the filters were extracted with EDTA/ethanol/saline $(1: 9: 10, \mathrm{v} / \mathrm{v} / \mathrm{v})$. The extract was subjected to high voltage electrophoresis, and from the distribution of the radioactivity the amount of ADP was calculated (•- $\bullet$. The obtained plot was corrected for the non-saturated component by subtraction of the linear part of the curve $(\mathrm{O}-\mathrm{O})$. (B) Distribution of points in a Scatchard plot after correction for the non-saturated part of the curve $(0 \ldots-\infty)$.

to adenine nucleotides [5]. This possibility was ruled out in a binding study in which $1 \mathrm{mM}$ of unlabeled adenosine was added. No influence on the accumulation of radioactivity was observed. Degradation of ADP to adenosine and also to inosine or hypoxanthine within the incubation time normally used was also unlikely because these metabolites were never detected. A few experiments for demonstration of ADP binding to intact platelets were performed with a centrifugation technique (see Methods). A similar binding curve was found as with the filtration technique, while association constant and maximum binding for the high affinity components were in the same range (not shown).

TABLE I

ADP BINDING PARAMETERS FOR PLATELETS AND PLATELET MEMBRANES

Values are means \pm S.D. of the number of experiments given in parentheses

\begin{tabular}{|c|c|c|}
\hline & $K_{\mathrm{a}}\left(\mathrm{M}^{-1}\right)$ & $\begin{array}{l}\text { Binding sites } \\
\text { per platelet }\end{array}$ \\
\hline $\begin{array}{l}\text { Platelets (ADP only, } n=7 \text { ) } \\
\text { Platelets (total binding, } n=12 \text { ) } \\
\text { Platelets (total binding; high ADP concn., } n=2 \text { ) }\end{array}$ & $\begin{array}{l}(0.18 \pm 0.09) \cdot 10^{6} \\
(0,28 \pm 0.13) \cdot 10^{6} \\
0.49 \cdot 10^{3}\end{array}$ & $\begin{array}{l}29400 \pm 12000 \\
60900 \pm 26200 \\
32.8 \cdot 10^{6}\end{array}$ \\
\hline Platelet membranes (ADP only, $n=19$ ) & $(0.90 \pm 0.56) \cdot 10^{6}$ & $\begin{array}{l}206.9 \text { pmol ADP } \\
\text { bound per } \mathrm{mg} \\
\text { protein }=80000 \\
\text { per platelet }\end{array}$ \\
\hline
\end{tabular}




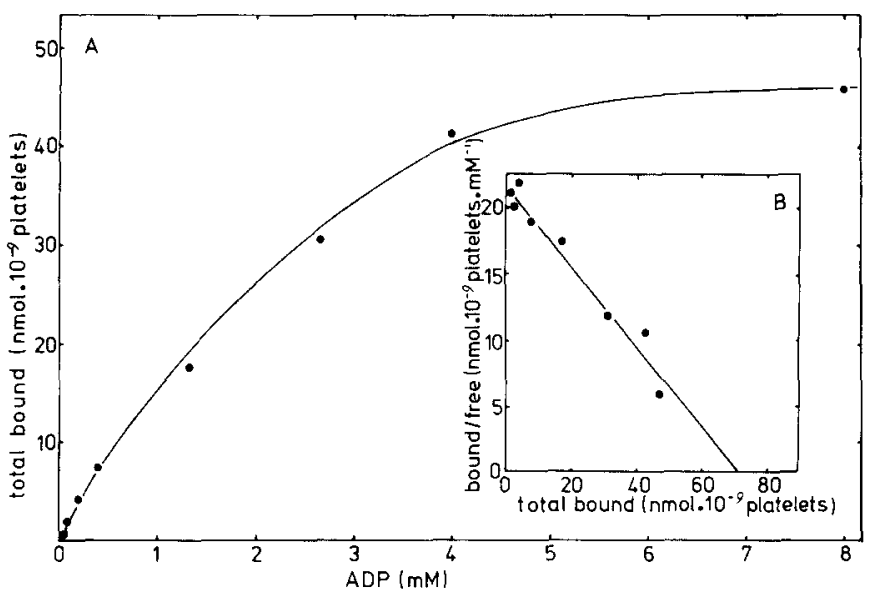

Fig. 3. Concentration dependence of $\left[{ }^{14} \mathrm{C}\right] \mathrm{ADP}$ binding to intact platelets at $\mathrm{m} M$ concentrations. Binding of ADP to intact washed (gel-filtered) human blood platelets was guided as described under Methods. The total radioactivity adhered to the filters was determined directly. Inset: Distribution of the points in a Scatchard plot.

\section{$\left[{ }^{14} \mathrm{C}\right] A D P$-binding to isolated platelet membranes}

Association of $\left[{ }^{14} \mathrm{C}\right] \mathrm{ADP}$ with isolated platelet membranes was more rapid than with intact cells. The plateau level was reached within 5 min. This plateau level was found at all concentrations used. The concentration dependence was similar to that in intact platelets (Fig. 4). Binding parameters were derived from

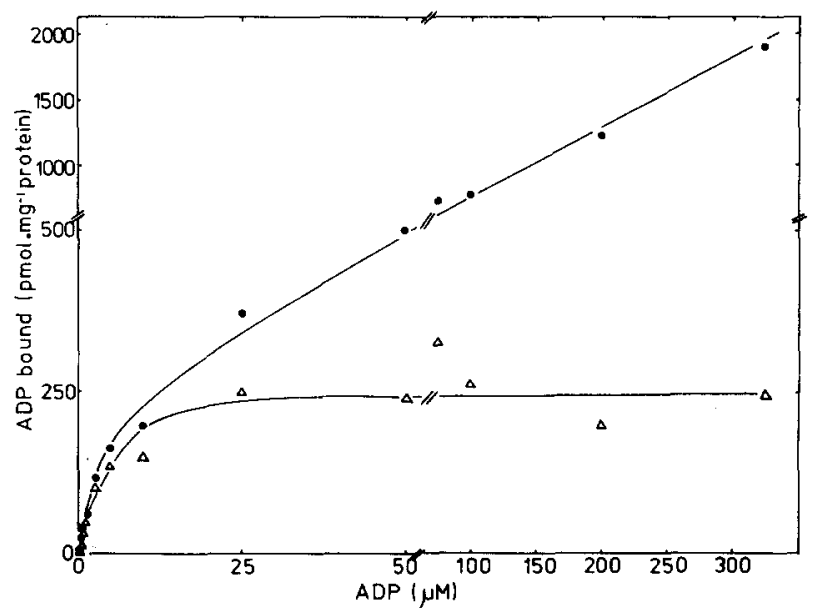

Fig. 4. Concentration dependence of ADP binding to washed platelet membranes. Washed human blood platelet membranes were incubated at $37^{\circ} \mathrm{C}$ with different $\left[{ }^{14} \mathrm{C}\right] \mathrm{ADP}$ concentrations, for $10 \mathrm{~min}$. Samples were filtered in triplicate over Millipore filters, and from the filter-associated radioactivity the amount of binding was computed (- - ). The obtained plot was corrected for the non-saturated component by subtraction of the linear part of the curve $(\Delta-\triangle)$. 


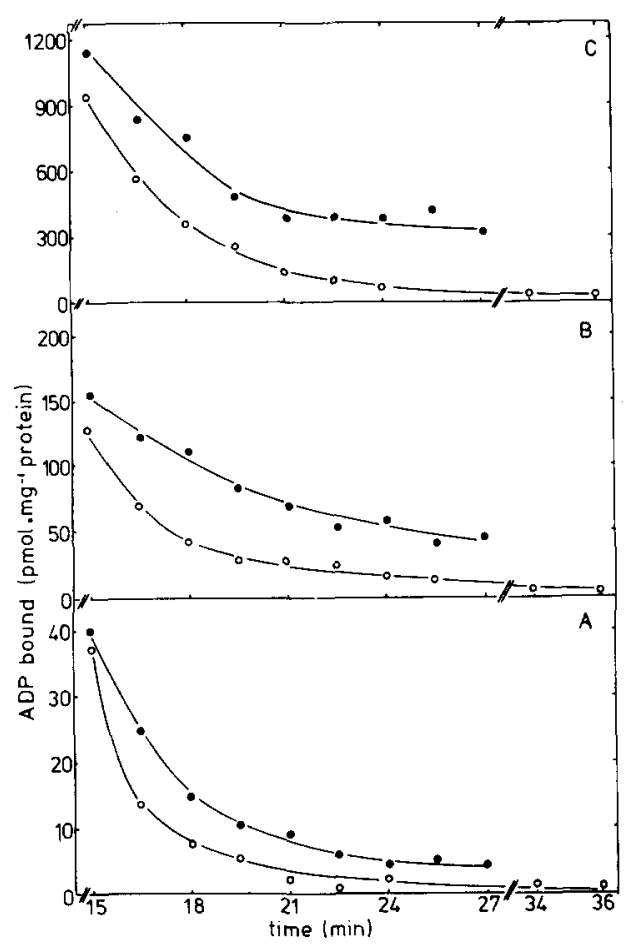

Fig. 5. Effect of dilution on ADP binding. Washed human blood platelet membranes were incubated for $10 \mathrm{~min}$ with three different $\left[{ }^{14} \mathrm{C}\right] \mathrm{ADP}$ concentrations and the equilibrium binding was determined. The incubation mixture was than diluted with 9 vols. saline containing non-radioactive ADP in a 10-fold concentration compared to the preincubation mixture $(\longrightarrow)$ and saline containing ADP in a 1000-fold concentration compared to the preincubated mixture $(0-\infty)$. Samples were taken at the indicated times and from the filter associated radioactivity the amount binding was computed. A: $0.5 \mu \mathrm{M} ; \mathrm{B}: 10$ $\mu \mathrm{M} ; \mathrm{C}: 200 \mu \mathrm{M}\left[{ }^{14} \mathrm{C}\right] \mathrm{ADP}$.

Scatchard plots of the high affinity system (Table I). From the maximum binding of $206.9 \pm 65.9 \mathrm{pmol} / \mathrm{mg}$ protein and on the basis of $20 \%$ of platelet protein being membrane protein [25] and a yield of $45 \%$ of the protein (based on sialic acid and ${ }^{125}$ I-labeled Fab recovery) a number of binding sites for ADP of $80000 /$ platelet could be calculated. The degradation of ADP associated with isolated membranes was negligible (5-7\% within $20 \mathrm{~min}$ ) and mainly directed towards AMP. The specificity of $\left[{ }^{14} \mathrm{C}\right] \mathrm{ADP}$ binding to platelet membranes was demonstrated in experiments with leucocyte membranes*, which showed negligible binding.

The binding of ADP was reversible. Dilution of a platelet membrane suspension, after the plateau level had been reached, caused a large decrease in radioactivity associated with the membranes (Fig. 5, closed symbols). No difference in the rate of exchange of ADP was found for dilution with Tris-saline buffer, or Tris-saline buffer containing a 10- or 100-fold concentration of non-labeled

\footnotetext{
* Kindly provided by Dr. J. de Jong from our department.
} 
ADP. Complete dissociation of labeled ADP from the membranes was achieved after $20 \mathrm{~min}$ incubation with a 1000 -fold concentration of unlabeled ADP (Fig. 5, open symbols). The complete reversibility justified omission of a correction for non-specific binding. ADP binding to membranes appeared to be saturable at high (mM) ADP concentration, similarly to binding to intact platelets (not shown).

\section{Influence of temperature, $p H$ and ions}

Binding of ADP to membranes in the concentration range of the high affinity system $(0.625 \mu \mathrm{M})$ was not particularly temperature dependent: $Q_{10}=$ $1.10 \pm 0.07$ (mean \pm S.D., $n=9$ ). The binding in the range where the low affinity system is predominant, was more sensitive to temperature changes: $Q_{10}=$ $1.49 \pm 0.14$ (mean \pm S.D., $n=3$ ).

A symmetric $\mathrm{pH}$ optimum for binding of ADP to membranes was observed at 7.8 for the high affinity binding system $(0.625 \mu \mathrm{M})$ and at 6.8 for the low affinity system $(50 \mu \mathrm{M})$ in the presence of calcium ions. In the presence of EDTA no optimum was observed for both ADP concentrations.

The standard incubation medium for studying ADP binding to washed platelets and to isolated membranes contained $2 \mathrm{mM}$ calcium ions. Increasing the calcium concentrations at high and low ADP concentrations resulted in a stimulation of ADP binding, while increasing the magnesium concentration had no effect. The stimulating effect of calcium on ADP binding to membranes between 0 and $20 \mu \mathrm{M}$ ADP was observed at calcium concentrations above 100 $\mu \mathrm{M}$. Inhibition of calcium stimulated ADP binding was observed if the magnesium concentration was raised at a fixed calcium concentration (not shown). When calcium and magnesium were omitted and $2 \mathrm{mM}$ EDTA was added, the same level of binding was found for intact platelets, while with membranes $60-$ $80 \%$ of the level with $2 \mathrm{mM}$ calcium was found.

\section{Inhibition of $A D P$ binding to membranes}

The influence of various reagents that inhibit ADP-aggregation $[26,27]$ was tested. The results are summarized in Table II. $p$-Chloromercuribenzene sulfonate $(125 \mu \mathrm{M})$ inhibits the high affinity system completely, both in membranes and in intact cells. It was the only sulfhydryl reagent tested that had this effect. It also inhibited the low affinity system to a great extent. Acetylating sulfhydryl reagents like iodoacetamide and $N$-ethylmaleimide $(1 \mathrm{mM})$ were without effect.

Inhibitors of ADP-aggregation that are thought to act through the $3^{\prime}, 5^{\prime}$-cyclic AMP system [28] were also investigated. Adenosine, 2-chloroadenosine, nitrobenzylmercaptopurine riboside and cyclic AMP itself were without effect on both the high and low affinity system.

Various nucleoside diphosphates (GDP, UDP, CDP, dADP, dTDP, all used at $100 \mu \mathrm{M})$ that can induce aggregation of rabbit and human platelets $[15,29]$ were weak inhibitors of ADP binding at $0.625 \mu \mathrm{M}$ (Table II).

Several ATP and ADP analogs were tested for their influence on both ADP binding and aggregation. A direct comparison of the effects of these substances on both ADP induced responses with intact platelets appeared to be impossible, as in all cases NDP kinase activity interfered with binding. Intact platelets, sus- 
TABLE II

\section{EFFECTS OF DIFFERENT COMPOUNDS ON ADP BINDING}

Determination of binding of ADP to isolated membranes was performed as described under Methods. The values presented in the table designate mean percentage \pm S.D. of control, from different experiments (numbers in parentheses) with different membrane preparations. The indicated concentrations are final concentrations.

\begin{tabular}{|c|c|c|c|}
\hline \multirow[t]{2}{*}{ Compound } & \multirow{2}{*}{$\begin{array}{l}\text { Concen- } \\
\text { tration }\end{array}$} & \multicolumn{2}{|c|}{ ADP concentrations } \\
\hline & & $0.625 \mu \mathrm{M}$ & $\mathbf{5 0} \mu \mathbf{M}$ \\
\hline$p$-Chloromercuribenzene sulfonate & $125 \mu \mathrm{M}$ & $20.4 \pm 10.2(3)$ & $38.0 \pm 6.0(3)$ \\
\hline Iodoacetamide & $1 \mathrm{mM}$ & $98.2 \pm 11.4(3)$ & $87.2 \pm 27.6(3)$ \\
\hline$N$-Ethylmaleimide & $1 \mathrm{mM}$ & $92.3 \pm 0.9(3)$ & $86.1 \pm 15.6(3)$ \\
\hline Adenosine & $20 \mathrm{M}$ & $104.0 \pm 25.4(5)$ & $104.3 \pm 27.9(3)$ \\
\hline 2-Chloroadenosine & $100 \mu \mathrm{M}$ & $98.9 \pm 12.5(5)$ & $92.6 \pm 20.9(3)$ \\
\hline Nitrobenzylmercaptopurine riboside & $50 \mu \mathrm{M}$ & $100.1 \pm 18.8(5)$ & $120.5 \pm 56.4(3)$ \\
\hline Cyclic AMP & $2 \mu \mathrm{M}$ & $97.8 \pm 21.1(5)$ & $109.2 \pm 23.8(3)$ \\
\hline GDP & $100 \mu \mathrm{M}$ & $44.1 \pm 1.8(3)$ & $101.2 \pm 27.8(3)$ \\
\hline UDP & $100 \mu \mathrm{M}$ & $50.6 \pm 6.0(3)$ & $110.8 \pm 32.8(3)$ \\
\hline CDP & $100 \mu \mathrm{M}$ & $44.2 \pm 0.3(3)$ & $98.2 \pm 14.5(3)$ \\
\hline dATP & $100 \mu \mathrm{M}$ & $41.4 \pm 7.7(3)$ & $98.7 \pm 25.3(3)$ \\
\hline dTDP & $100 \mu \mathrm{M}$ & $99.4 \pm 8.1(3)$ & $99.3 \pm 16.0$ \\
\hline $\operatorname{AMP}\left(\mathrm{CH}_{2}\right) \mathrm{PP}$ & $100 \mu \mathrm{M}$ & $116.1 \pm 23.1(4)$ & $70.9 \pm 15.0(4)$ \\
\hline $\operatorname{AMP}\left(\mathrm{CH}_{2}\right) P$ & $100 \mu \mathrm{M}$ & $65.8 \pm 16.8(3)$ & $79.1 \pm 17.0(3)$ \\
\hline
\end{tabular}

pended in a glucose containing medium (see Methods), probably supplied ATP for extracellular formation of $\left[{ }^{14} \mathrm{C}\right] \mathrm{ATP}$ from $\left[{ }^{14} \mathrm{C}\right] \mathrm{ADP}$. This $\left[{ }^{14} \mathrm{C}\right] \mathrm{ATP}$ production was not dependent on extracellular magnesium or calcium nor was it inhibited by non-hydrolysable ATP analogs. Therefore, a comparison was made of ADP induced aggregation with ADP binding to isolated platelet membranes.

ATP is a strong competitive inhibitor of platelet aggregation and shape change induced by ADP [30,31]. The effect of ATP on ADP binding to membranes was studied under conditions in which NDP kinase was inactive. The inhibitory effect was therefore studied in a magnesium free system. ATP appeared to be a powerful competitive inhibitor of ADP binding and of ADP induced aggregation (Table III). Apart from ATP, only IDP and (2-O-thio)ADP caused powerful inhibition of ADP binding and aggregation with comparable $K_{\mathrm{i}}$ values (Table III). A special case is represented by $\mathrm{FSO}_{2}-\mathrm{Bz}$-Ado. This compound has been reported as competitive inhibitor of the shape change [32]. This was confirmed by our experiments (Table III). However, only weak inhibition of ADP binding could be detected. This lack of inhibition was shown in the presence and absence of calcium ions [33]. Several binding experiments with this inhibitor were carried out with intact platelets. In this case more inhibition was seen, however, this is misleading because the solvent of $\mathrm{FSO}_{2}-\mathrm{Bz}$-Ado, dimethyl formamide, deeply influenced binding: a completely different binding curve was found (not shown). AMP was a competitive inhibitor of aggregation $\left(K_{\mathrm{i}} 26.0 \mu \mathrm{M}\right)$, confirming another report [34], but inhibited binding much less $\left(K_{\mathrm{i}} 390 \mu \mathrm{M}\right)$. 
TABLE III

EFFECTS OF ATP AND ANALOGS OF ATP AND ADP ON [ $\left.{ }^{14} \mathrm{C}\right]$ ADP BINDING AND ADP INDUCED AGGREGATION

Determination of binding of ADP to isolated membranes was performed as described under Methods. For aggregation experiments, blood platelets were washed by gel filtration and aggregation of platelets was followed as described under Methods. The used inhibitor concentrations were $25 \mu \mathrm{M}$ (ATP only), $50 \mu \mathrm{M}$, $100 \mu \mathrm{M}, 200 \mu \mathrm{M}$ (not for ATP). The results of the aggregation experiments were derived from Dixon plots, those of binding experiments from Eadie-Hofstee plots. Values are expressed as mean \pm S.D. with number of experiments in parentheses.

\begin{tabular}{|c|c|c|}
\hline Compound & $K_{\mathrm{i}}$ for binding & $K_{\mathrm{i}}$ for aggregation \\
\hline ATP & $1.1(6)$ & $1.8 \pm 0.9 \quad(4)$ \\
\hline $\operatorname{AMPP}\left(\mathrm{CH}_{2}\right) \mathrm{P}$ & $370.2 \pm 178.8(4)$ & $132.8 \pm 37.8 \quad(4)$ \\
\hline IDP & $4.7 \pm \quad 1.0(3)$ & $15.2 \pm 6.5$ \\
\hline (2-O-thio)ADP & $4.7(3)$ & $21.1 \pm 4.5 \quad(4)$ \\
\hline $\mathrm{FSO}_{2} \mathrm{Bz}$-Ado & $218.3 \pm 58.8(5)$ & $17.2 \pm 6.0(12)$ \\
\hline AMP & $390.0 \pm 220.0(3)$ & $26.0 \pm 5.9 \quad(6)$ \\
\hline
\end{tabular}

Two other nucleotide analogs were tested for their influence on ADP binding and aggregation. $\operatorname{AMP}\left(\mathrm{CH}_{2}\right) \mathrm{PP}$ had no influence on binding nor aggregation while AMP $\left(\mathrm{CH}_{2}\right) \mathrm{P}$ had a very weak effect on binding and aggregation at low ADP concentrations. The results of these substances concerning ADP binding are shown in Table II.

\section{Nucleoside diphosphokinase kinetics}

NDP kinase was present in isolated membranes as demonstrated by $\left[{ }^{14} \mathrm{C}\right] \mathrm{ATP}$ formation from $\left[{ }^{14} \mathrm{C}\right] \mathrm{ADP}$, in the presence of magnesium and a nucleoside triphosphate. With washed platelets $\left[{ }^{14} \mathrm{C}\right] \mathrm{ATP}$ formation from $\left[{ }^{14} \mathrm{C}\right] \mathrm{ADP}$ was also demonstrated without magnesium or a nucleoside triphosphate but ATP formation was enhanced in the presence of an extracellular nucleoside triphosphate. No concomitant increase in $\left[{ }^{14} \mathrm{C}\right] \mathrm{AMP}$ was detected.

The formation of $\left[{ }^{14} \mathrm{C}\right] \mathrm{ATP}$ was linear with time for at least 4 min at low $\left[{ }^{14} \mathrm{C}\right] \mathrm{ADP}$ and ATP concentration. At higher $\left[{ }^{14} \mathrm{C}\right] \mathrm{ADP}$ concentrations the linearity with time extended to more than $10 \mathrm{~min}$. The initial rate of $\left[{ }^{14} \mathrm{C}\right] \mathrm{ATP}$ formation was determined by taking samples at $0.5,2,4$ and 10 min and assaying the distribution of radioactivity between $\left[{ }^{14} \mathrm{C}\right] \mathrm{ADP}$ and $\left[{ }^{14} \mathrm{C}\right] \mathrm{ATP}$ by high voltage electrophoresis of EDTA/ethanol extracts. The concentration dependence for $\left[{ }^{14} \mathrm{C}\right] \mathrm{ADP}$ of the NDP kinase catalyzed reaction at three different ATP concentrations is shown in Fig. 6A. At each ATP concentration the reaction showed Michaelis-Menten kinetics: with increasing ATP the $K_{\mathrm{m}}$ and $V$ increased too. When the concentration dependency curves were converted into Lineweaver-Burk plots, three parallel lines were found (Fig. 6B). A plot of the derived reciprocal $K_{\mathrm{m}}$ and $V$ values went through the origin. When $\left[{ }^{14} \mathrm{C}\right] \mathrm{ATP}$ was used as the varying substrate with three ADP concentrations, the same observations were made: $K_{\mathrm{m}}$ and $V$ increased with increasing ADP, parallel lines were found in Lineweaver-Burk plots and the plot of reciprocal $K_{\mathrm{m}}$ and $V$ values went through the origin. From three experiments, corrected $K_{\mathrm{m}}$ values were calculated after replotting the $V$ values against the fixed substrate concentra- 

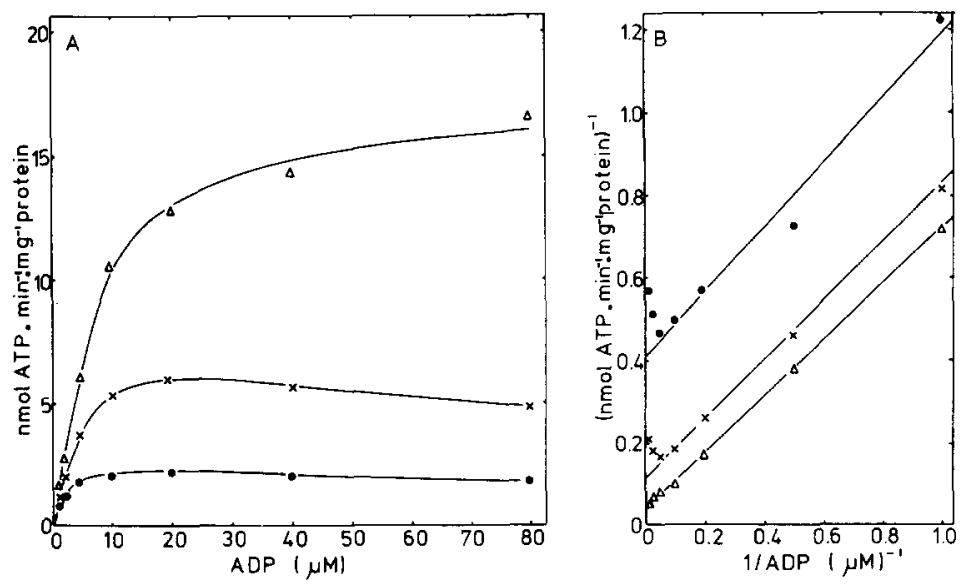

Fig. 6. (A) Concentration dependence of nucleoside diphosphokinase. Washed human blood platelet membranes were incubated at $37^{\circ} \mathrm{C}$ with various $\left[{ }^{14} \mathrm{C}\right.$ ]ADP concentrations and three fixed ATP concentrations $(\bullet-, 2 \mu \mathrm{M} ; X \longrightarrow \triangle, 10 \mu \mathrm{M} ; \triangle \longrightarrow \triangle, 50 \mu \mathrm{M}$ ATP). Samples were taken after $30 \mathrm{~s}, 2,4$ and $10 \mathrm{~min}$ and these were extracted with EDTA/ethanol. The amount $\left[{ }^{14} \mathrm{C}\right] \mathrm{ATP}$ formed was determined from the distribution of the radioactivity with the help of high voltage electrophoresis of the extracts. (B) Lineweaver-Burk plot of the results shown in Fig. $6 \mathrm{~A}, \circ, 2 \mu \mathrm{M} ; \mathrm{X}, 10 \mu \mathrm{M}$; and $\Delta, 50 \mu \mathrm{M}$ ATP. Because of the substrate inhibition the values obtained with the two lowest ATP and the two highest ADP concentrations were not included in the calculation of the intercepts.

tions. The $K_{\mathrm{m}}$ values were $13.3 \pm 6.4 \mu \mathrm{M}$ and $6.2 \pm 3.2 \mu \mathrm{M}$ (mean \pm S.D.) for ATP and ADP respectively. The enzyme was inhibited in a non-competitive way by AMP with ADP as variable substrate, however a competitive inhibition by AMP was observed when ADP and ATP concentrations were varied in a fixed ratio. The $K_{\mathrm{i}}$ value was $340 \mu \mathrm{M}$. These results suggest that platelet NDP kinase reacts via a ping pong bi bi reaction mechanism [35]. The enzyme had a $Q_{10}$ value of $1.41 \pm 0.04$ (mean \pm S.D., $n=4$ ) and an activity optimum at $\mathrm{pH}$ 8.0.

\section{Discussion}

In this study we present the kinetics of ADP binding to intact washed platelets as well as to isolated membranes. Of the two classes of binding systems described here the high affinity system is the most likely candidate to be the ADP receptor for the induction of shape change and aggregation. The ADPbinding curves for the high affinity systems (Figs. 2 and 4) are similar to the concentration dependence curve for aggregation and shape change $[30,36]$. The number of high affinity binding sites (calculated on the basis of total bound radioactivity) was of the same order of magnitude as reported for shape change and aggregation induced by ADP [37,38]. The dissociation constants also correspond well with the $K_{\mathrm{m}}$ values for ADP induced shape change and aggregation $[9,30]$. The $\mathrm{pH}$ optimum for binding, $(\mathrm{pH} \mathrm{7.8)}$, at low concentrations of ADP is also in the same range as aggregation induced by ADP ( $\mathrm{pH} \mathrm{8.0,} \mathrm{ref.} \mathrm{34).} \mathrm{The}$ cation dependence for ADP binding is not entirely similar to that for shape change and aggregation. Shape change is independent on extracellular divalent 
cations [30,36] but aggregation has a requirement for calcium ions [39]. ADP binding to platelets and membranes occurs to the same extent in the absence of calcium, and even in $2 \mathrm{mM}$ EDTA, but binding is enhanced at increasing calcium concentrations. Stimulation of ADP binding was only found at calcium concentrations much higher than needed to form a calcium-ADP complex ([Ca$\mathrm{ADP}] /[\mathrm{Ca}][\mathrm{ADP}]$ about 3000). Consequently, calcium stimulation of binding can be attributed to a process other than complex formation. The inhibitory effect of increasing magnesium ion concentration at a single calcium concentration is not reflected in the ion dependence of shape change and aggregation.

Similarities between shape change and aggregation and binding through the high affinity binding system also exist in the response to several inhibitors. ATP is a powerful competitive inhibitor of shape change and aggregation $\left(K_{\mathrm{i}} 20\right.$ and $3 \mu \mathrm{M}[30,31])$, and also of binding to the high affinity system $\left(K_{\mathrm{i}} 2.1 \mu \mathrm{M}\right.$, Table III) and these $K_{i}$ values are in good agreement. IDP is a competitive inhibitor of aggregation and shape change [15] and also of binding (Table III). Also a close correlation exists between the $K_{\mathrm{i}}$ values for aggregation and binding for AMPP $\left(\mathrm{CH}_{2}\right) \mathrm{P}$ and (2-O-thio)ADP. The former appeared to be a relatively effective inhibitor of ADP aggregation [40], but at the high concentration of $1 \mathrm{mM}$. Although less extensively tested, $\mathrm{AMP}\left(\mathrm{CH}_{2}\right) \mathrm{P}$ appeared to be weak inhibitor of binding and aggregation. Only at high concentrations could this compound cause shape change and aggregation [41]. The adenosine analog $\mathrm{FSO}_{2}$-Bz-Ado has been reported to inhibit the rate of ADP induced shape change. This behaviour was attributed to the interaction of this compound with adenine nucleotide binding sites [32,33]. However, it was not shown that $\mathrm{FSO}_{2}$-Bz-Ado inhibits incorporation of ADP in platelets or membranes. In our hands, this compound inhibited ADP induced aggregation, but it had only a very weak inhibiting action on ADP binding. An explanation for this difference might be found in the steric requirements for the ADP receptor involved in shape change and aggregation. From all compounds tested, only a few had inhibiting power; all effective inhibitors had a pyrophosphate group (ATP, IDP, (2-O-thio)ADP) while compounds with changes in the pyrophosphate group (AMPP $\left.\left(\mathrm{CH}_{2}\right) \mathrm{P}, \operatorname{AMP}\left(\mathrm{CH}_{2}\right) \mathrm{PP}, \operatorname{AMP}\left(\mathrm{CH}_{2}\right) \mathrm{P}\right)$ were ineffective. Consequently it is less probable for $\mathrm{FSO}_{2}-\mathrm{Bz}$-Ado to bind to the ADP receptor. The influence of $\mathrm{FSO}_{2}$-Bz-Ado on $\mathrm{ADP}$ induced shape change and aggregation might be explained by interaction with other proteins involved in aggregation, after induction of shape change by ADP. A possible candidate for such a protein might be myosin or a $100000 M_{\mathrm{r}}$ protein [33]. The discrepancy in inhibition by AMP of binding and aggregation may be explained by the difference in influence of AMP on shape change and aggregation, the former being much less inhibited [34]. The slight inhibitory effect of several nucleoside diphosphates (GDP, UDP, CDP) at $100 \mu \mathrm{M}$ on ADP binding agrees well with the notion that the weak aggregation caused by these substances at $800 \mu \mathrm{M}$ may be due to a weak agonistic effect at the site of the ADP receptor [15]. $p$-Chloromercuribenzene sulfonate, a SHgroup reactant inhibiting shape change and aggregation induced by ADP [26], inhibited the high affinity and the low affinity binding systems in conformity with its less specific effect.

In the present study we observed a close similarity between binding to intact platelets and to isolated membranes. This is mainly caused by the use of 
washed platelets that prevented the extracellular breakdown of ADP to nucleosides and purines [16], and the subsequent intracellular accumulation of radiolabel due to incorporation of adenosine and hypoxanthine, which may have influenced previous investigations [8,9]. The close correlation between ADP binding to the high affinity binding site, and ADP induced shape change and aggregation as described in this paper is a confirmation of a report, in which the influence of a drug, Ticlopidine, on ADP binding was shown [42]. After the drug had been ingested by volunteers, only the high affinity binding component was found while shape change was normal in these platelets.

Our results on binding to isolated membranes are at variance with those of Nachman and Ferris [10]. They described a single receptor with a $K_{\mathrm{a}}$ of 6.5 . $10^{6} \mathrm{M}^{-1}$ and a maximum binding of 100000 molecules per platelet. The binding required calcium or magnesium and was inhibited by 2 -chloroadenosine and to a lesser extent by ATP and AMP. The binding showed appreciable temperature dependence and reached a plateau level only after $1 \mathrm{~h}$ incubation. The differences with our results may be due to different techniques used for platelet membrane isolation. Nachman and Ferris [10] used a no clearance pestle homogenization according to Marcus [43] in the presence of $1 \mathrm{mM}$ EDTA. The time course of their binding suggests that their membranes may have contained ADP and that they studied exchange rather than binding. Of note is their suggestion that ADP might bind to actomyosin associated with the membranes. We tried to find indications for this by removing part of the membrane associated actomysin by extraction with $0.6 \mathrm{M} \mathrm{KCl}$. However, this procedure did not influence ADP binding (results not shown).

Membranes that were prepared with the same technique as in the present study, were utilized by Legrand and Caen [12]. The presence of a low affinity binding system was not observed by these authors as they used concentrations below $8 \mu \mathrm{M}$ ADP. Their results on the influence of divalent cations are at variance with ours. They found no requirement for calcium and normal binding in the presence of EDTA. We found a definite stimulation by calcium and an inhibitory action of magnesium ions. An explanation for this difference may be found in the isolation procedure. Legrand and Caen [12] used a 30\% sucrose density step ultracentrifugation while we used a $20 \%$ metrizoate density step. Different types of membranes may have been isolated, since metrizoate at the used concentration has a lower osmolarity than $30 \%$ sucrose. In a recent study Adler and Handin [13] described ADP binding to a platelet membrane derived protein fraction. Their results resemble ours, as far as the high affinity binding component is concerned. However, they used too low ADP concentrations to detect the low affinity binding system. Moreover no connection was made between ADP binding to intact platelets, membranes and the membrane derived soluble protein fraction.

Guccione et al. [14] and Packman et al. [15] demonstrated that intact platelets contain a nucleosidediphosphate kinase as an ectoenzyme. These authors raised the hypothesis that this NDP kinase could be the ADP receptor [14,15, 44]. Because of this, we decided to study NDP kinase and to compare it to the ADP binding systems. This study was carried out with isolated membranes. The enzyme was magnesium dependent and showed only activity when a nucleoside triphosphate was added. The corrected $K_{\mathrm{m}}$ for ADP was $6.2 \mu \mathrm{M}$, for ATP 13.3 
$\mu \mathrm{M}$ and AMP was a competitive inhibitor. This kinetic behaviour of platelet NDP kinase is consistent with NDP kinases from other sources, although the affinity for ADP and ATP is higher for platelet NDP kinase [45].

Although the characteristics of the high affinity ADP binding system and of NDP kinase do not suggest that they are similar (no influence of AMP on ADP binding - AMP inhibits NDP kinase, calcium stimulates ADP binding - NDP kinase requires magnesium ions) the possibility that NDP kinase is the functional receptor for ADP cannot be excluded. Calcium stimulated only at free ion concentrations much larger than found physiologically, and inhibition of NDP kinase by AMP is at least a weak one $\left(K_{\mathrm{i}}\right.$ about $\left.0.34 \mathrm{mM}\right)$. The results presented in this paper show that ADP binds to intact platelets as well as to isolated membranes with the same characteristics. Consequently it may be possible to isolate ADP binding protein(s), starting from platelet membranes. This may be preferable because they contain much less contaminating ADP binding proteins than an intact platelet. Attempts to isolate such ADP binding proteins from membranes are currently in progress in our laboratory.

\section{Acknowledgement}

This study was supported by the Foundation for Medical Research (FUNGO) which is subsidized by the Netherlands Organization for the Advancement of Pure Scientific Research (ZWO).

\section{References}

1 Gaarder, A., Jonson, J., Laland, S., Hellem, A. and Owren, P. (1961) Nature 192, 531

2 Salzman, E.W. and Chambers, D.A. (1965) Nature 206, 727-728

3 Born, G.V.R. (1965) Nature 206, 1121-1122

4 Rozenberg, M.C. and Holmsen, H. (1968) Biochim. Biophys. Acta 155, 342-352

5 Sixma, J.J., Lips, J.P.M., Trieschnigg, A.M.C. and Holmsen, H. (1976) Biochim. Biophys. Acta 443, $33-48$

6 Holmsen, H. and Rozenberg, M.C. (1968) Biochim. Biophys. Acta 155, 326-341

7 Holmsen, H. and Day, H.J. (1971) Ser. Haematol, 6, 28-59

8 Boullin, D.J., Green, A.R. and Price, K.S. (1972) J. Physiol. 221, 415-426

9 Born, G.V.R. and Feinberg, H. (1975) J. Physiol. (London) 251, 803-816

10 Nachman, R.L. and Ferris, B. (1974) J. Biol. Chem. 249, 704-710

11 Barber, A.J. and Jamieson, G.A. (1970) J. Biol. Chem. 245, 6357-6365

12 Legrand, C. and Caen, J.P. (1976) Haemostasis 5, 231-238

13 Adler. J.R. and Handin, R.J. (1979) J. Biol. Chem. 254, 3866-3872

14 Guccione, M.A., Packham, M.A., Kinlough-Rathbone, R.L. and Mustard, J.F. (1971) Blood 37, 542555

15 Packham, M.A., Guccione, M.A., Perry, D.W. and Mustard, J.F. (1974) Am. J. Physiol. 227, 11431148

16 Packham, M.A., Ardlie, M.G. and Mustard, J.F. (1969) Am. J. Physiol. 21 7, 1009-1017

17 Walsh, P.N. (1972) Brit. J. Haematol. 22, 205-217

18 Nachman, R.L. and Ferris, B. (1972) J. Biol. Chem. 247, 4468-4475

19 Lowry, O.H., Rosebrough, M.J., Farr, A.L. and Randall, R.J. (1951) J. Biol. Chem. 193, 265-275

20 Holmsen, H. (1972) Ann. New York Acad. Science 201, 109-121

21 Holmsen, H. and Weiss, H. (1970) Brit. J. Haematol, 19, 643-649

22 Dixon, M. and Webb, E.C. (1967) in the Enzymes (2nd edn.), pp. 328-330, Longman Green and Co., London

23 Scatchard, G. (1949) Ann. N.Y. Acad. Sci. 103, 773-784

24 Neame, K.D. and Richards, T.G. (1972) in Elementary Kinetics of Membrane Carrier Transport, pp. 41-56 and 80-95, Blackwell Scientific Publications, Ox ford

25 Sixma, J.J. and Lips, J.P.M. (1978) Thromb. Haemost. 39, 328-337 
26 Hampton, J.R. and Mitchell, J.R.A. (1966) Nature 210, 1000-1002

27 Mills, D.C.B. (1974) in Platelets and Thrombosis (Sherry, S. and Scriabine, A., eds.), pp. 57-67, University Park Press, Baltimore

28 Haslam, R.J. (1973) Sem. Haematol, 6, 333-350

29 Salzman, E.W., Chambers, D.A. and Neri, L.L. (1967) Fed. Proc. 26, 759

30 Born, G.V.R. (1970) J. Physiol. 209, 487-511

31 MacFarlane, D.E. and Mills, D.C.B. (1975) Blood 46, 309-320

32 Bennett, J.S., Colman, R.F. and Colman, R.W. (1978) in Mechanisms of Hemostasis and Thrombosis (Mielke, C.H. and Rodvien, R., eds.), pp. 167-181, Symposia Specialists Medical Book, Miami

33 Bennett, J.S., Colman, R.F. and Colman, R.W. (1978) J. Bibl. Chem. 253, 7346-7354

34 Packham, M.A., Guccione, M.A., Perry, D.W., Kinlough-Rathbone, R.L. and Mustard, J.F. (1972) Am. J. Physiol. 223, 420-424

35 Cleland, W.W. (1963) Biochim. Biophys. Acta 67, 104-137

36 Skoza, L., Zucker, M.B. and Jerushalmy, Z. (1967) Thromb. Diath. Haemorrh. 18, 713-725

37 O'Brien, J.R. (1962) J. Clin. Pathol. 15, 446-452

38 Hampton, J.R. and Mitchell, J.R.A. (1966) Nature 211, 245-246

39 Hovig, T. (1964) Thromb. Diath. Haemorrh. 12, 179-200

40 Born, G.V.R. and Foulks, J.G. (1977) Br. J. Pharm. 61, 87-89

41 Horak, H. and Barton, P.G. (1974) Biochim. Biophys. Acta 373, $471-480$

42 Lips, J.P.M., Sixma, J.J., Schiphorst, M.E. (1980) Thromb. Res., in the press

43 Marcus, A.J., Zucker, D., Safier, L.B. and Ullman, H.L. (1966) J. Clin. Invest. 45, 14-28

44 Mustard, J.F. (1975) in Biochemistry and Pharmacology of Platelets, Ciba Foundation Symposium Vol. 35, pp. 47-75, Excerpta Medica, Amsterdam

45 Parks, R.E. and Agarwall, R.P. (1973) in The Enzymes (Boyer, P., ed.) 3rd edn., pp. 307-333, Academic Press, New York 